\section{BMJ Open Respiratory Research}

\title{
Is the use of two versus one long-acting bronchodilator by patients with COPD associated with a higher risk of acute coronary syndrome in real-world clinical practice?
}

\author{
Lianne Parkin (D , ${ }^{1,2}$ Sheila Williams, ${ }^{1}$ David Barson, ${ }^{1,2}$ Katrina Sharples, ${ }^{2,3,4}$ \\ Simon Horsburgh, ${ }^{1,2}$ Rod Jackson, ${ }^{5}$ Jack Dummer (1) ${ }^{2,4}$
}

\begin{abstract}
To cite: Parkin L, Williams S, Barson D, et al. Is the use of two versus one long-acting bronchodilator by patients with COPD associated with a higher risk of acute coronary syndrome in real-world clinical practice?. BMJ Open Resp Res 2021;8:e000840. doi:10.1136/ bmjresp-2020-000840
\end{abstract}

- Additional material is published online only. To view please visit the journal online (http://dx.doi.org/10.1136/ bmjresp-2020-000840)

Received 22 November 2020 Revised 3 December 2020 Accepted 7 December 2020

\section{Check for updates}

(C) Author(s) (or their employer(s)) 2021. Re-use permitted under CC BY-NC. No commercial re-use. See rights and permissions. Published by BMJ.

For numbered affiliations see end of article.

Correspondence to Associate Professor Lianne Parkin;

lianne.parkin@otago.ac.nz

\section{ABSTRACT}

Background Cardiovascular comorbidity is common among patients with chronic obstructive pulmonary disease (COPD) and there is concern that long-acting bronchodilators (long-acting muscarinic antagonists (LAMAs) and long-acting beta ${ }_{2}$ agonists (LABAs)) may further increase the risk of acute coronary events. Information about the impact of treatment intensification on acute coronary syndrome (ACS) risk in real-world settings is limited. We undertook a nationwide nested case-control study to estimate the risk of ACS in users of both a LAMA and a LABA relative to users of a LAMA. Methods We used routinely collected national health and pharmaceutical dispensing data to establish a cohort of patients aged $\geq 45$ years who initiated long-acting bronchodilator therapy for COPD between 1 February 2006 and 30 December 2013. Fatal and non-fatal ACS events during follow-up were identified using hospital discharge and mortality records. For each case we used risk set sampling to randomly select up to 10 controls, matched by date of birth, sex, date of cohort entry (first LAMA and/or LABA dispensing), and COPD severity.

Results From the cohort ( $\mathrm{n}=83417$ ), we identified 5399 ACS cases during 281292 person-years of follow-up. Compared with current use of LAMA therapy, current use of LAMA and LABA dual therapy was associated with a higher risk of ACS (OR $1.28(95 \% \mathrm{Cl} 1.13$ to 1.44$))$. The OR in an analysis restricted to fatal cases was $1.46(95 \% \mathrm{Cl}$ 1.12 to 1.91).

Conclusion In real-world clinical practice, use of two versus one long-acting bronchodilator by people with COPD is associated with a higher risk of ACS.

\section{INTRODUCTION}

Coronary heart disease and chronic obstructive pulmonary disease (COPD) are leading causes of health loss and death worldwide ${ }^{1}$ and in New Zealand. $^{2-4}$ Cardiovascular comorbidity is common among patients with COPD. ${ }^{5}$ This can partially be explained by shared risk factors such as smoking and age, however COPD also appears to be an

\section{Key messages}

In patients with chronic obstructive pulmonary disease (COPD), is concomitant use of a long-acting muscarinic antagonist (LAMA) and a long-acting beta $_{2}$ agonist (LABA) associated with a higher risk of acute coronary syndrome in the real-world setting of clinical practice than use of a LAMA alone?

- The combined use of a LAMA and a LABA, rather than a LAMA alone, could increase the risk of acute coronary syndrome by about $30 \%$ in patients with COPD, a population already at high risk of acute coronary events.

- The research has important implications for healthcare providers and patients who are considering the potential benefits and harms of using two versus one long-acting bronchodilator.

independent risk factor for coronary heart disease. ${ }^{5}$

Successive editions of the Global Initiative for Chronic Obstructive Lung Disease Guidelines have recommended concomitant use of a long-acting muscarinic antagonist (LAMA) and long-acting beta ${ }_{2}$ agonist (LABA) if COPD symptoms are not well controlled on one long-acting bronchodilator ${ }^{6}$; and a recent American Thoracic Society clinical practice guideline strongly recommended the combined use of a LAMA and LABA, rather than monotherapy, in patients with dyspnoea or exercise intolerance. ${ }^{7}$ However, there is concern that long-acting bronchodilators might further increase the risk of acute coronary events in patients with COPD. ${ }^{8}$ This is important, given that the impact of these drugs (singly or in combination) on clinically important outcomes is relatively modest $^{7} 9-15$ and patients with COPD are 
more likely to die from coronary events than from respiratory failure. ${ }^{16}$

Although the findings from randomised controlled trials (RCTs) appear to be reassuring about the cardiovascular safety of long-acting bronchodilators, the trials were usually underpowered for safety endpoints, and patients with pre-existing cardiovascular disease and other comorbidities were frequently excluded. ${ }^{17}$ Metaanalyses of those RCTs have also had limited power to examine cardiovascular risk ${ }^{9-15}$ and the authors of one review ${ }^{9}$ reported they were unable to undertake a metaanalysis of serious cardiovascular events because of a lack of consistency in reporting those outcomes. These limitations have prompted calls for more inclusive RCTs, as well as large observational studies, in real-world settings of clinical care. ${ }^{17}$

We undertook a national study to estimate the risk of acute coronary syndrome (ACS) in users of both a LAMA and a LABA relative to users of a LAMA. We also sought to explore the risk of ACS according to history of ischaemic cardiovascular disease, ethnicity, and concomitant use of an inhaled corticosteroid (ICS).

\section{METHODS}

\section{Study design}

Case-control study, nested within a national cohort of patients who initiated long-acting bronchodilator therapy for COPD.

\section{Data sources and derivation of study cohort}

The study was based on linked data from the Ministry of Health's National Collections, ${ }^{18}$ including the Pharmaceutical Collection (records of all claims by communitybased pharmacists for the dispensing of prescription drugs which are publicly funded-most medicines prescribed in New Zealand), the National Health Index Collection (demographic data), the National Minimum Dataset (public hospital and publicly funded private hospital discharges), the Mortality Collection (inpatient and community-based deaths), and the New Zealand Cancer Registry (all cancers, except non-melanoma skin cancers).

We took several steps to derive the study cohort (figure 1). First, the Ministry identified all patients who were dispensed a LAMA, LABA, or LABA/ICS product in New Zealand at least once between 1 February 2005 and 31 December 2013 (end of follow-up) and provided us with linked demographic, health and pharmaceutical dispensing data for these patients. The date of the first dispensing of a long-acting bronchodilator was taken as the cohort entry date. We then excluded patients with incorrectly linked records $(0.4 \%)$, those aged $<45$ years at cohort entry and those with a history of at least one hospital discharge diagnosis of asthma and no COPD diagnoses (to minimise the inadvertent inclusion of patients prescribed a LABA or LABA/ICS inhaler solely for asthma), those who entered the cohort between 1
February 2005 and 31 January 2006 (to avoid the bias that can arise from the inclusion of patients already using the drugs of interest at the start of follow-up), and those who entered the cohort on 31 December 2013 (to ensure that we identified ACS events that occurred after the first dispensing of a long-acting bronchodilator).

\section{Summarising LAMA and LABA exposure in the study cohort}

We summarised exposure to long-acting bronchodilators during follow-up for each member of the study cohort, as outlined in online supplemental figures 1-3, table 1, and online supplemental table 1.

\section{Nested case-control analyses \\ Identification of cases}

Cohort members were classified as a case if there was a record between cohort entry and 31 December 2013, of (1) a hospital admission in which there was a principal or additional discharge diagnosis coded to any of

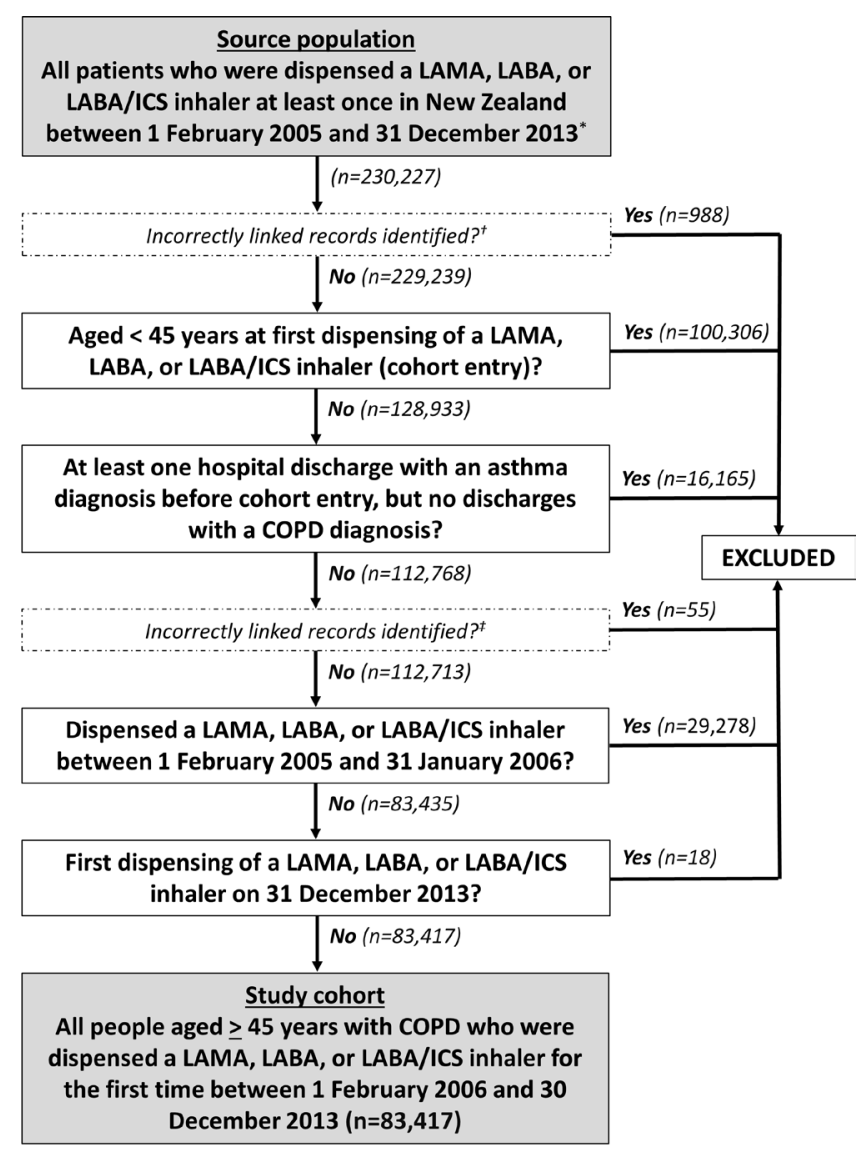

\footnotetext{
* LAMA/LABA combination products were not available during this period

${ }^{+}$Identified on basis of incompatible cohort entry date and date of birth and/or date of death

${ }^{\ddagger}$ Identified by examining records with mismatch between patient category on dispensing record and age at dispensing

Figure 1 Derivation of the study cohort. COPD, chronic obstructive pulmonary disease; ICS, inhaled corticosteroid; LABA, long-acting beta ${ }_{2}$ agonist; LAMA, long-acting muscarinic antagonist.
} 


\begin{tabular}{|c|c|}
\hline $\begin{array}{l}\text { Exposure categories and } \\
\text { regimens }\end{array}$ & Products included in regimen \\
\hline \multicolumn{2}{|c|}{ LAMA and LABA dual therapy } \\
\hline LAMA+LABA/ICS & Concurrent use of LAMA single-agent product and LABA/ICS combination product \\
\hline LAMA+LABA+ICS & Concurrent use of three single-agent products (LAMA, LABA and ICS) \\
\hline LAMA+LABA & Concurrent use of LAMA and LABA single-agent products \\
\hline \multicolumn{2}{|l|}{ LAMA therapy } \\
\hline LAMA & Use of LAMA single-agent product only \\
\hline LAMA+ICS & Concurrent use of LAMA and ICS single-agent products \\
\hline \multicolumn{2}{|l|}{ LABA therapy } \\
\hline LABA & Use of LABA single-agent product only \\
\hline LABA+ICS & Concurrent use of LABA and ICS single-agent products \\
\hline LABA/ICS & Use of LABA/ICS combination product only \\
\hline \multicolumn{2}{|l|}{ ICS monotherapy* } \\
\hline ICS & Use of ICS single-agent product only \\
\hline
\end{tabular}

*By design, all cohort members had used a long-acting bronchodilator before the episode of ICS monotherapy.

ICS, Inhaled corticosteroid; LABA, long-acting beta ${ }_{2}$ agonist; LAMA, long-acting muscarinic antagonist.

the following International Statistical Classification of Diseases and Related Health Problems, Australian Modification, (ICD-10-AM) rubrics: I200 (unstable angina), I21 (acute myocardial infarction), or I22 (subsequent myocardial infarction, $<28$ days after a previous myocardial infarction); or (2) death and any of the above ICD-10-AM rubrics were coded as the underlying cause of death. We took the date of the first ACS event during follow-up as the index date for each case and their matched controls.

\section{Selection of controls}

For each case, we used risk set sampling to randomly select up to 10 controls, matched by date of birth $( \pm 365$ days), sex, date of cohort entry ( \pm 183 days), and COPD severity (online supplemental table 2 ).

\section{Ascertainment of user status on the index date}

We classified individuals as current users of LAMA and LABA dual therapy, LAMA therapy, or LABA therapy if use occurred in the 30-day period before the index date (online supplemental figure 3). Conversely, those whose most recent therapy ended $>30$ days before the index date were classified as unexposed, as were patients whose only therapy in the 30 days before the index date was an ICS. Similarly, for the analyses exploring the impact of concomitant ICS use, we classified individuals as current users if the relevant exposure occurred in the 30 days before the index date. Individuals exposed to more than one LAMA-containing or LABA-containing therapy in the 30 days before the index date were classified according to the therapy they used closest to that date.

We ascertained user status without knowledge of whether an individual was a case or a control.

\section{Other covariates}

We used data from the National Collections to derive covariates for descriptive purposes and multivariate analyses. Covariates chosen a priori for inclusion in the adjusted models were demographic characteristics (self-identified ethnicity categorised according to the Ministry of Health Ethnicity Data Protocols ${ }^{19}$ and an area-based measure of deprivation, NZDep $06^{20}$ ), Charlson comorbidity score (based on hospital admissions in the preceding 5 years), a history of conditions associated with an increased risk of subsequent cardiovascular events (ACS, other ischaemic heart disease, raised blood pressure, dyslipidaemia, heart failure, ischaemic stroke, transient ischaemic attack, diabetes), a history of conditions that might have influenced prescribing decisions about LAMA, LABA, and ICS products (life-threatening arrhythmia, benign prostatic hypertrophy/bladder outflow obstruction, hyperthyroidism, closed-angle glaucoma, osteoporotic fracture), and the use of medications which increase or decrease the risk of ACS (non-steroidal anti-inflammatories, oral theophylline, lipid-lowering agents, antiplatelets, anticoagulants, blood pressure-lowering medications).

\section{Statistical methods}

The primary analysis explored the risk of ACS in users of LAMA and LABA dual therapy (LAMA and LABA with or without ICS), and of LABA therapy (LABA with or without ICS), relative to LAMA therapy (LAMA with or without ICS). Secondary analyses were undertaken based on cases for whom ACS was the principal diagnosis and for those whose ACS event was fatal. We also undertook secondary analyses stratified by history of ischaemic cardiovascular disease (history/no history of ACS, other ischaemic heart disease, ischaemic stroke, and/or transient ischaemic 
attack at any time before the index date), ethnicity (Māori, the indigenous people/non-Māori), and ICS exposure in the 30 days before the index date (exposed/ not exposed).

Conditional logistic regression was used in the primary analysis to estimate unadjusted and adjusted ORs and 95\% CIs. For the secondary analyses stratified by history of ischaemic cardiovascular disease, ethnicity, and ICS exposure, we used logistic regression and adjusted for the matching factors in addition to the other covariates. Chained equations, ${ }^{21}$ using all the data included in the analysis, were used to estimate the missing ethnicity and deprivation data (which were assumed to be missing at random). Fifty sets of data were imputed using a run-in of 150 .

Analyses were carried out in Stata V.15.0.

\section{Estimation of incidence rates}

Crude incidence rates of ACS in users of LAMA and LABA dual therapy, LAMA therapy, and LABA therapy were estimated by dividing the number of cases which occurred during an episode of use of the relevant therapy by the total person-years of exposure for that therapy (censored at the index date for cases); $95 \%$ CIs were calculated using the mid-P exact method.$^{22}$ We also calculated age-adjusted and sex-adjusted rates with $95 \% \mathrm{CIs},{ }^{23}$ as well as crude and age-adjusted and sex-adjusted rates for Māori and non-Māori, with the age distribution of the total New Zealand population as the standard.

\section{Patient and public involvement}

Patients were not involved in the design, or conduct, or reporting, or dissemination plans of our research.

\section{RESULTS}

Overall, we identified 83417 patients who initiated use of a LAMA, LABA, or LAMA/ICS inhaler between 1 February 2006 and 30 December 2013. A total of 5422 patients had an ACS event during 281292 person-years of follow-up, however controls could not be found for 23 of these cases and they were excluded from the casecontrol analyses.

Table 2 and online supplemental table 3 show the characteristics of the 5399 cases and 51563 controls included in the case-control analyses. Similar patterns of hospital discharge diagnoses and medication use were seen relative to the index date (online supplemental table 4).

The results of the primary analysis are shown in table 3 . In the adjusted matched analysis, current users of LAMA and LABA dual therapy were 1.3 times as likely as current users of LAMA therapy to have an ACS event (OR 1.28 (95\% CI 1.13 to 1.44)). Relative to current users of LAMA therapy, patients who were not currently using a long-acting bronchodilator were less likely to have an ACS event (OR 0.84 (95\% CI 0.76 to 0.92$)$ ), while there was no difference in risk between current users of LABA therapy and current users of LAMA therapy (OR 1.0 (95\% CI 0.91 to 1.10)). An unmatched analysis, adjusted for the matching factors, as well as the other covariates, yielded very similar estimates. Analyses confined to cases with a principal diagnosis of ACS (online supplemental table 5) and fatal ACS events (online supplemental table 6) also produced similar findings; the matched adjusted ORs for LAMA and LABA dual therapy versus LAMA therapy were 1.22 (95\% CI 1.05 to 1.41 ) and 1.46 (95\% CI 1.12 to 1.91 ), respectively. There was no evidence of a different pattern of results for the comparisons between LAMA and LABA dual therapy, LABA therapy, and LAMA therapy over time ( $\mathrm{p}=0.06$, online supplemental table 7 ).

The results of the analyses stratified by a history of ischaemic cardiovascular disease (online supplemental table 8 ) and by ethnicity (online supplemental table 9) were consistent with those of the primary analysis and there was no evidence of effect modification $(\mathrm{p}=0.3$ and $\mathrm{p}=0.4$, respectively). The findings for the analysis stratified by current use of an ICS differed somewhat (online supplemental table 10); while the unmatched adjusted OR for LAMA and LABA dual therapy versus LAMA therapy in the ICS-exposed stratum was similar to that found in the primary analysis, the corresponding OR in the stratum with no ICS exposure was consistent with no effect although the numbers were small and the $95 \%$ CI was correspondingly wide. The interaction effect was not significant $(\mathrm{p}=0.7)$.

Overall, the age-adjusted and sex-adjusted incidence rates for LAMA and LABA dual therapy and LAMA therapy were 25.1 (95\% CI 20.5 to 29.6 ) and 22.4 (95\% CI 18.3 to 26.4) per 1000 person-years, respectively, giving an absolute excess risk of 2.7 per 1000 person-years (online supplemental table 11). Among Māori, users of LAMA therapy had a higher rate than users of LAMA and LABA dual therapy, although the numbers of cases were small and the estimates less precise.

\section{DISCUSSION}

\section{Principal findings}

In this large national study of patients with COPD who commenced treatment with long-acting bronchodilators, current users of LAMA and LABA dual therapy were about 1.3 times as likely to be admitted to hospital with, and/or die from, ACS as current users of LAMA therapy. Very similar estimates were found in secondary analyses based on cases for whom ACS was the principal diagnosis, those with fatal ACS, and in analyses stratified by history of ischaemic cardiovascular disease and ethnicity.

\section{Findings in relation to previous studies}

Most RCTs that compared the use of two versus one long-acting bronchodilator and had at least 12 months' follow-up were too small to provide meaningful estimates of ACS risk. ${ }^{24-26}$ Meta-analyses that included such RCTs, as well as those with shorter follow-up time, also had limited power. ${ }^{13-15}$ Two of those meta-analyses examined the risk 
Table 2 Key characteristics* of cases and controls; values are numbers (percentages) unless stated otherwise

\begin{tabular}{|c|c|c|}
\hline Characteristic & Cases $(n=5399)$ & Controls $(n=51563)$ \\
\hline Median age at cohort entry (years, IQR) & $74.3(65.8-80.8)$ & $73.8(65.6-80.2)$ \\
\hline Median follow-up from cohort entry to index date (years, IQR) & $1.6(0.6-3.1)$ & $1.6(0.6-3.1)$ \\
\hline \multicolumn{3}{|l|}{ Sex } \\
\hline Female & $2388(44.2)$ & $22709(44.0)$ \\
\hline Male & $3011(55.8)$ & $28854(56.0)$ \\
\hline \multicolumn{3}{|l|}{ Charlson comorbidity score at cohort entry $\dagger$} \\
\hline 0 & $2224(41.2)$ & $29214(56.7)$ \\
\hline 1 & $1133(21.0)$ & $11090(21.5)$ \\
\hline 2 & $823(15.2)$ & $5614(10.9)$ \\
\hline$\geq 3$ & $1219(22.6)$ & $5645(11.0)$ \\
\hline \multicolumn{3}{|l|}{ COPD severity at cohort entry } \\
\hline Mild/moderate & $3401(63.0)$ & $33460(64.9)$ \\
\hline Severe & $1164(21.6)$ & $10990(21.3)$ \\
\hline Very severe & $834(15.5)$ & $7113(13.8)$ \\
\hline \multicolumn{3}{|l|}{ Hospital discharge diagnoses at any time before cohort entry } \\
\hline Acute coronary syndrome & $1883(34.9)$ & $7539(14.6)$ \\
\hline Other ischaemic heart disease & $2081(38.5)$ & $9297(18.0)$ \\
\hline Raised blood pressure & $2523(46.7)$ & $15076(29.2)$ \\
\hline Dyslipidaemia & $1305(24.2)$ & $6091(11.8)$ \\
\hline Heart failure & $1267(23.5)$ & $6402(12.4)$ \\
\hline Life-threatening arrhythmia & $630(11.7)$ & $3302(6.4)$ \\
\hline Ischaemic stroke & $223(4.1)$ & $1430(2.8)$ \\
\hline Transient ischaemic attack & $265(4.9)$ & $1526(3.0)$ \\
\hline Diabetes & $956(17.7)$ & $5174(10.0)$ \\
\hline Benign prostatic hypertrophy/bladder outflow obstruction & $374(6.9)$ & $3031(5.9)$ \\
\hline \multicolumn{3}{|l|}{ Medication use in 6 months before cohort entry } \\
\hline Statin & $2552(47.3)$ & $17438(33.8)$ \\
\hline Antiplatelet & 2669 (49.4) & $18077(35.1)$ \\
\hline Blood pressure lowering & $3970(73.5)$ & $31189(60.5)$ \\
\hline Non-steroidal anti-inflammatory & $813(15.1)$ & 7757 (15.0) \\
\hline Oral theophylline & $54(1.0)$ & $445(0.9)$ \\
\hline
\end{tabular}

*Full characteristics in online supplemental table 3.

†Based on hospital discharge diagnoses in the 5 years before cohort entry.

COPD, chronic obstructive pulmonary disease; IQR, Interquartile range.

of a composite outcome of all-cause non-fatal serious adverse events and did not report on the risk of cardiac events, ${ }^{1314}$ while a network meta-analysis based on just 322 severe cardiac adverse events among 20736 patients in 22 RCTs reported an OR of 0.98 (95\% CI 0.78 to 1.25$)$ for the LAMA and LABA versus LAMA comparison. ${ }^{15}$

Our findings are consistent with a safety analysis in an RCT that was unpublished at the time the data were extracted for the network meta-analysis. In the IMPACT trial, a multicentre RCT that compared the rate of moderate or severe COPD exacerbations during a 12-month follow-up period in 10355 patients allocated to one of three combination inhalers, ischaemic coronary events occurred more frequently in the LAMA/LABA and LAMA/LABA/ICS arms than in the LABA/ICS arm; the rates per 1000 person-years were 30.6, 26.1 and 18.5, respectively. ${ }^{27}$

A few observational studies have compared the risk of cardiovascular events in patients concurrently using a LAMA and a LABA relative to users of one long-acting bronchodilator, ${ }^{28-32}$ however the primary analyses in four investigations ${ }^{28-30}{ }^{32}$ focused on various composite outcomes (which collectively included coronary heart disease, arrhythmia, heart failure, ischaemic and haemorrhagic stroke, and transient ischaemic attack) rather than acute coronary events. In the fifth study, which explored 
Table 3 Risk of acute coronary syndrome (ACS) in relation to long-acting bronchodilator exposure status in 30 days before index date

\begin{tabular}{|c|c|c|c|c|c|}
\hline Exposure status & $\begin{array}{l}\text { Cases (No } \\
(\%))\end{array}$ & $\begin{array}{l}\text { Controls (No } \\
(\%))\end{array}$ & $\begin{array}{l}\text { Matched } \\
\text { unadjusted OR } \\
(95 \% \mathrm{Cl})\end{array}$ & $\begin{array}{l}\text { Matched adjusted } \\
\text { OR }^{\star}(95 \% \mathrm{Cl})\end{array}$ & $\begin{array}{l}\text { Unmatched } \\
\text { adjusted OR† } \\
(95 \% \mathrm{Cl})\end{array}$ \\
\hline $\begin{array}{l}\text { LAMA and LABA dual } \\
\text { therapy }\end{array}$ & $641(11.9)$ & $4592(8.9)$ & 1.25 (1.11 to 1.41$)$ & $1.28(1.13$ to 1.44$)$ & $1.25(1.11$ to 1.41$)$ \\
\hline LAMA therapy & $678(12.6)$ & $6044(11.7)$ & 1.0 & 1.0 & 1.0 \\
\hline LABA therapy & 2017 (37.4) & 18590 (36.1) & 0.97 (0.89 to 1.07$)$ & $1.00(0.91$ to 1.10$)$ & $1.01(0.92$ to 1.11$)$ \\
\hline Unexposed & 2063 (38.2) & 22337 (43.3) & 0.83 (0.75 to 0.91$)$ & 0.84 (0.76 to 0.92$)$ & 0.85 (0.77 to 0.93$)$ \\
\hline
\end{tabular}

*Adjusted for ethnicity; NZDep06; Charlson comorbidity score; hospital discharge diagnosis before cohort entry of asthma, ACS; hospital discharge diagnosis before cohort entry and (separately) between cohort entry and index date of any ischaemic heart disease, raised blood pressure, dyslipidaemia, heart failure, life-threatening arrhythmia, ischaemic stroke, transient ischaemic attack, diabetes, benign prostatic hypertrophy/bladder outflow obstruction; hospital discharge diagnosis at any time before index date of hyperthyroidism, closedangle glaucoma, osteoporotic fracture; use in 6 months before cohort entry and (separately) in 6 months before the index date of statin, antiplatelet, blood pressure lowering, non-steroidal anti-inflammatory,and theophylline therapy.

†Adjusted for the above variables and the matching factors (date of birth, sex, date of cohort entry, and COPD severity). $\ddagger$ No long-acting bronchodilator use in 30 days before index date.

COPD, chronic obstructive pulmonary disease; LABA, long-acting beta ${ }_{2}$ agonist; LAMA, long-acting muscarinic antagonist.

the risk of four cardiovascular outcomes in the primary analysis, the acute myocardial infarction estimate was based on a relatively small number of cases $(n=415)$ and a $37 \%$ increase in risk could not be ruled out (HR 1.12 (95\% CI 0.92 to 1.37$)) .{ }^{31}$ The sole observational study to have reported estimates for concomitant LAMA and LABA use relative to LAMA found a weak association for a composite cardiovascular outcome in the primary analysis, although this could have been a chance finding (HR 1.13 (95\% CI 0.60 to 2.13)). ${ }^{28}$ Importantly, the first exposure was carried forward in the analysis and that could have led to an underestimation of the association because of misclassification of exposure status. In a secondary analysis that considered changes in treatment over time, the association was stronger although the CI was still wide (HR 1.26 (95\% CI 0.74 to 2.15$)$ ).

In line with other observational studies that examined the risk of composite cardiovascular outcomes or ACS, we also observed a lower risk of ACS in patients who were not currently using a long-acting bronchodilator $^{33} 34$ and comparable ACS risk between users of LAMA therapy and users of LABA therapy. ${ }^{33-38}$

\section{Strengths and limitations}

This study has several strengths. First, New Zealand has a universal healthcare system, and information about the dispensing of publicly funded medicines (which included all LABA, LABA/ICS, and LAMA products that were available in New Zealand during the study period) from community pharmacies, hospital discharge diagnoses, and causes of death are all recorded in the Ministry of Health's National Collections and can be linked across the collections using a unique patient identifier (the National Health Index). This allowed us to identify a national cohort of new users of long-acting bronchodilators and to obtain information about individuals' medication use and medical history both before cohort entry and during follow-up. Second, we are confident that the primary comparison (LAMA and LABA dual therapy versus LAMA therapy) was based on patients with COPD, because funded access to LAMA products during the study period was restricted to those with a spirometry-confirmed diagnosis of COPD. Third, our study included substantially more ACS cases than previous investigations and this allowed more precise estimates of risk. Fourth, to minimise potential confounding by indication, cases and controls were matched on severity of COPD and we addressed the primary aim in a matched analysis and adjusted for severity of COPD in the secondary unmatched analyses. In addition, we explored the degree to which worsening of COPD during follow-up (which, independently of medication, might have been associated with a higher risk of ACS) was associated with escalation to LAMA and LABA dual therapy. Among patients with mild/moderate COPD at cohort entry who were initially treated with LAMA therapy, only 19\% escalated to LAMA and LABA dual therapy within 90 days following the first indication of increasing COPD severity; the majority remained on LAMA therapy for at least 9 months. The corresponding proportion for those initially on LABA therapy was only $6 \%$. Given this prescribing behaviour, confounding by indication is unlikely to explain much of the observed increased risk of ACS.

The study also has several limitations. First, medicines dispensed in hospitals are not recorded in the Pharmaceutical Collection; however, the absence of this information is unlikely to have had a substantive impact on our study because inpatient stays for COPD are generally of short duration ${ }^{3}$ and patients collect medicines prescribed at discharge from community pharmacies. Second, we did not have access to the results of investigations to validate the diagnosis of ACS; however, there 
is good agreement between ACS diagnoses recorded in the national hospital discharge database and those documented by clinicians in the All New Zealand Acute Coronary Syndrome Quality Improvement registry. ${ }^{39}$ Third, we could not find controls for 23 older cases; however, the exclusion of this small number of cases should not have distorted our findings. Fourth, our definition of exposure to long-acting bronchodilators was based on dispensed inhalers and, as with all studies that do not involve direct observation of medicine consumption, it is impossible to know whether patients actually used these as directed. It is possible that cohort members who were dispensed LAMA and LABA dual therapy were less likely to have adhered to their prescribed regimen than users of LAMA therapy as this would have involved the use of two inhalers (combined LAMA/LABA products were not available during the study period); the impact of this would be to have been to underestimate risk. Fifth, while we adjusted for hospital discharge diagnoses of diabetes, hyperlipidaemia, and raised blood pressure, as well as the use of lipid and blood pressure-lowering medication, we did not have access to the results of glycated haemoglobin or total cholesterol/high-density lipoprotein ratio tests, or to blood pressure measurements, so we cannot rule out residual confounding by these factors. Nor did we have information on some well-established risk factors such as smoking, obesity, and family history of premature cardiovascular disease. However, our inability to adjust for smoking status is unlikely to be an important source of confounding in this study of patients with COPD, as a very high proportion of cohort members are likely to have been current or former smokers. Finally, the analysis stratified by current ICS use had limited power.

\section{CONCLUSION}

Given that the use of two versus one long-acting bronchodilator is associated with relatively modest improvements in patient-relevant health outcomes, our finding that LAMA and LABA dual therapy was associated with a higher risk of ACS than use of LAMA therapy has important implications for clinical decisions about the potential benefits and harms of treatment intensification.

\section{Author affiliations}

${ }^{1}$ Department of Preventive and Social Medicine, Otago Medical School -

Dunedin Campus, University of Otago, Dunedin, New Zealand

${ }^{2}$ Pharmacoepidemiology Research Network, University of Otago, Dunedin, New Zealand

${ }^{3}$ Department of Mathematics and Statistics, University of Otago, Dunedin, New Zealand

${ }^{4}$ Department of Medicine, Otago Medical School - Dunedin Campus, University of Otago, Dunedin, New Zealand

${ }^{5}$ Department of Epidemiology and Biostatistics, Faculty of Medical and Health Sciences, University of Auckland, Auckland, New Zealand

Acknowledgements We thank Analytical Services at the New Zealand Ministry of Health for providing the necessary data.
Contributors All authors contributed to the study conception and design, and to the interpretation of the findings. LP, SW, DB, and KS contributed to the acquisition and analysis of data. LP drafted the manuscript. SW, DB, KS, SH, RJ, and JD critically revised the manuscript.

Funding The research was funded by a Strategic Research Grant from the Department of Preventive and Social Medicine, Otago Medical School-Dunedin Campus, University of Otago.

Disclaimer The funder had no role in the study design; in the collection, analysis, and interpretation of data; in the writing of the report; or in the decision to submit the article for publication.

Competing interests None declared.

Patient consent for publication Not required.

Ethics approval The study was approved by the Southern Health and Disability Ethics Committee (reference: 15/STH/66).

Provenance and peer review Not commissioned; externally peer reviewed.

Data availability statement No data are available. The authors are not permitted to share the data directly with third parties. Enquiries about access to data from the National Collections may be sent to data-enquiries@health.govt.nz.

Supplemental material This content has been supplied by the author(s). It has not been vetted by BMJ Publishing Group Limited (BMJ) and may not have been peer-reviewed. Any opinions or recommendations discussed are solely those of the author(s) and are not endorsed by BMJ. BMJ disclaims all liability and responsibility arising from any reliance placed on the content. Where the content includes any translated material, BMJ does not warrant the accuracy and reliability of the translations (including but not limited to local regulations, clinical guidelines, terminology, drug names and drug dosages), and is not responsible for any error and/or omissions arising from translation and adaptation or otherwise.

Open access This is an open access article distributed in accordance with the Creative Commons Attribution Non Commercial (CC BY-NC 4.0) license, which permits others to distribute, remix, adapt, build upon this work non-commercially, and license their derivative works on different terms, provided the original work is properly cited, appropriate credit is given, any changes made indicated, and the use is non-commercial. See: http://creativecommons.org/licenses/by-nc/4.0/.

\section{ORCID iDs}

Lianne Parkin http://orcid.org/0000-0002-6824-6176

Jack Dummer http://orcid.org/0000-0003-1581-6857

\section{REFERENCES}

1 World Health Organization. Global health estimates 2016: disease burden by cause, age, sex, by country and by region, 2000-2016. Geneva: World Health Organization, 2018. www.who.int/healthinfo/ global_burden_disease/estimates/en/index1.html

2 Ministry of Health. Health loss in New Zealand 1990-2013: a report from the New Zealand Burden of Diseases, Injuries and Risk Factors Study. Wellington: Ministry of Health, 2016. www.health.govt.nz/ publication/health-loss-new-zealand-1990-2013

3 Ministry of Health. Publicly funded hospital discharges - 1 July 2016 - 30 June 2017. Wellington: Ministry of Health, 2019. www.health. govt.nz/publication/publicly-funded-hospital-discharges-1-july2016-30-june-2017. (Accessed 1 June 2020).

4 Ministry of Health. Mortality 2017 data tables. Wellington: Ministry of Health, 2019. www.health.govt.nz/publication/mortality-2017-datatables. (Accessed 1 June 2020).

5 Chen W, Thomas J, Sadatsafavi M, et al. Risk of cardiovascular comorbidity in patients with chronic obstructive pulmonary disease: a systematic review and meta-analysis. Lancet Respir Med 2015;3:631-9.

6 Global Initiative for Chronic Obstructive Lung Disease. Pocket guide to COPD diagnosis, management, and prevention: a guide for health care professionals, 2020. https://goldcopd.org/gold-reports/ (Accessed 1 June 2020).

7 Nici L, Mammen MJ, Charbek E, et al. Pharmacologic management of chronic obstructive pulmonary disease. An official American Thoracic Society Clinical Practice Guideline. Am J Respir Crit Care Med 2020;201:e56-69.

8 Woodruff PG. Double-edged sword? JAMA Intern Med 2013;173:1184-5.

9 Karner C, Chong J, Poole P. Tiotropium versus placebo for chronic obstructive pulmonary disease. Cochrane Database Syst Rev 2012;7:CD009285. 
10 Kew KM, Mavergames C, Walters JA. Long-acting beta2-agonists for chronic obstructive pulmonary disease. Cochrane Database Syst Rev 2013;10:CD010177.

$11 \mathrm{Ni} \mathrm{H}$, Soe Z, Moe S. Aclidinium bromide for stable chronic obstructive pulmonary disease. Cochrane Database Syst Rev 2014;9:CD010509.

$12 \mathrm{Ni} \mathrm{H}$, Htet A, Moe S. Umeclidinium bromide versus placebo for people with chronic obstructive pulmonary disease (COPD). Cochrane Database Syst Rev 2017;6:CD011897.

13 Farne HA, Cates CJ. Long-acting beta2-agonist in addition to tiotropium versus either tiotropium or long-acting beta2-agonist alone for chronic obstructive pulmonary disease. Cochrane Database Syst Rev 2015;10:CD008989.

$14 \mathrm{Ni} \mathrm{H}$, Moe S, Soe Z. Combined aclidinium bromide and long-acting beta2-agonist for chronic obstructive pulmonary disease (COPD). Cochrane Database Syst Rev 2018;12:CD011594.

15 Oba Y, Keeney E, Ghatehorde N. Dual combination therapy versus long-acting bronchodilators alone for chronic obstructive pulmonary disease (COPD): a systematic review and network meta-analysis. Cochrane Database Syst Rev 2018;12:CD012620.

16 Mannino DM, Doherty DE, Sonia Buist A. Global Initiative on Obstructive Lung Disease (GOLD) classification of lung disease and mortality: findings from the Atherosclerosis Risk in Communities (ARIC) study. Respir Med 2006;100:115-22.

17 Lahousse L, Verhamme KM, Stricker BH, et al. Cardiac effects of current treatments of chronic obstructive pulmonary disease. Lancet Respir Med 2016;4:149-64.

18 Ministry of Health. Collections. Wellington: Ministry of Health, 2020. www.health.govt.nz/nz-health-statistics/national-collections-andsurveys/collections. (Accessed 1 June 2020).

19 Ministry of Health. HISO 10001:2017 Ethnicity Data Protocols. Wellington: Ministry of Health, 2017. www.health.govt.nz/publication/ hiso-100012017-ethnicity-data-protocols

20 Salmond C, Crampton P, Atkinson J. NZDep2006 Index of Deprivation User's Manual. Wellington: University of Otago, 2007.

21 van Buuren S, Boshuizen HC, Knook DL. Multiple imputation of missing blood pressure covariates in survival analysis. Stat Med 1999;18:681-94.

22 Rothman KJ, Boice JD. Epidemiologic analysis with a programmable calculator. Bethesda, MD: National Institutes of Health, 1979: 1631-42.

23 Cochran W. Sampling techniques. 3rd edn. New York: Wiley, 1977.

24 Wedzicha JA, Banerji D, Chapman KR, et al. Indacaterolglycopyrronium versus salmeterol-fluticasone for COPD. N Engl J Med 2016;374:2222-34.

25 Buhl R, Magder S, Bothner U, et al. Long-term general and cardiovascular safety of tiotropium/olodaterol in patients with moderate to very severe chronic obstructive pulmonary disease. Respir Med 2017;122:58-66.

26 Donohue JF, Soong W, Wu X, et al. Long-term safety of aclidinium bromide/formoterol fumarate fixed-dose combination: results of a randomized 1-year trial in patients with COPD. Respir Med 2016;116:41-8.

27 Lipson DA, Barnhart F, Brealey N, et al. Once-daily single-inhaler triple versus dual therapy in patients with COPD. N Engl $J$ Med2018;378:1671-80.

28 Dong Y-H, Chang C-H, Gagne JJ, et al. Comparative cardiovascular and cerebrovascular safety of inhaled long-acting bronchodilators in patients with chronic obstructive pulmonary disease: a populationbased cohort study. Pharmacotherapy 2016;36:26-37.

29 Tsai M-J, Chen C-Y, Huang Y-B, et al. Long-acting inhaled bronchodilator and risk of vascular events in patients with chronic obstructive pulmonary disease in Taiwan population. Medicine 2015;94:e2306

30 Samp JC, Joo MJ, Schumock GT, et al. Risk of cardiovascular and cerebrovascular events in COPD patients treated with long-acting $\beta_{2}$-agonist combined with a long-acting muscarinic or inhaled corticosteroid. Ann Pharmacother 2017;51:945-53.

31 Suissa S, Dell'Aniello S, Ernst P. Concurrent use of long-acting bronchodilators in COPD and the risk of adverse cardiovascular events. Eur Respir J 2017;49:1602245.

32 Liou J-T, Lin CW, Tsai C-L, et al. Risk of severe cardiovascular events from add-on tiotropium in chronic obstructive pulmonary disease. Mayo Clin Proc 2018;93:1462-73.

33 Wang M-T, Liou J-T, Lin CW, et al. Association of cardiovascular risk with inhaled long-acting bronchodilators in patients with chronic obstructive pulmonary disease: a nested case-control study. JAMA Intern Med 2018;178:229-38.

34 Gershon A, Croxford R, Calzavara A, et al. Cardiovascular safety of inhaled long-acting bronchodilators in individuals with chronic obstructive pulmonary disease. JAMA Intern Med 2013;173:1175-85.

35 Suissa S, Dell'Aniello S, Ernst P. Long-acting bronchodilator initiation in COPD and the risk of adverse cardiopulmonary events: a population-based comparative safety study. Chest 2017;151:60-7.

36 Verhamme KMC, Afonso ASM, van Noord C, et al. Tiotropium handihaler and the risk of cardio- or cerebrovascular events and mortality in patients with COPD. Pulm Pharmacol Ther 2012;25:19-26.

37 Jara M, Lanes SF, Wentworth C, et al. Comparative safety of longacting inhaled bronchodilators. Drug Saf 2007;30:1151-60.

38 Jara M, Wentworth C, Lanes S. A new user cohort study comparing the safety of long-acting inhaled bronchodilators in COPD. BMJ Open 2012;2:e000841.

39 Kerr AJ, Lee M, Jiang Y, et al. High level of capture of coronary intervention and associated acute coronary syndromes in the All New Zealand Acute Coronary Syndrome Quality Improvement cardiac registry and excellent agreement with national administrative datasets (ANZACS-QI 25). N Z Med J 2019;132:19-29. 